\title{
ТЕРМОВЛАЖНОСТНЫЕ ПАРАМЕТРЫ ВОЗДУХА В ГОРНЫХ ВЫРАБОТКАХ ШАХТ ТКИБУЛИ
}

Ш.И.ОНИАНИ, О.Л. ЛАНЧАВа, Ю.Р. КСОВРЕЛИ (Ин-т горной механики АН ГССР)

Существует множество расчетных зависимостей $[1,4]$, с помощью которых можно прогнозировать температурные условия в горных выработках. Однако из-за недостаточной изученности массообмешшх процессов в шахтах нельзя с достаточной точностью прогнозировать значения относительной влажности в характерных точках вентиляционной сети. Эти значения берут из таблиц, составленных на основе идеализации шахтных условий и не всегда отражающих реальную картину. Указанное обстоятельство существенно снизает точность полученных результатов и, следовательно, качество прогноза климатических условий глубоких шахт, поэтому экспериментальное исследование тепло- и массообмена в капитальных выработках является актуальным.

В данной работе изложены результаты экспериментальных шахтных наблюдений, проведенных с целью: изучения и выявления закономерности протекания массообменных процессов в капитальных горных выработках; установления качественной и количественной картины изменения относительной влажности рудничного воздуха; выявления закономерности изменения коэффициента нестационарного теплообмена с учетом сезонных колебаний температуры в откаточных капитальных выработках; сопоставления экспериментальных значений коэффициента, нестационарного теплообмена с теоретическим; составления номограммы по определению поправки к коэффициенту нестационарного теплообмена, учитывающей влияние сезонных колебаний температуры воздуха.

Экспериментальные наблюдения проведены в течение 1978-1980 гг. на шахтах производственного объединения «Грузуголь". При наблюдениях стремились к выбору таких условий, для характеристики которых достаточно минимальное количество измеряемых величин. Например, при выборе опытных участков предпочтение отдавали тем выработкам, в которых отсутствовали утечки воздуха, местные источники тепла и влаги, изменение площади поперечного сечения и периметра выработки.

В каждом эксперименте влияние местных источников тепла было учтено дифференциально. В зависимости от времени года доля местных источников тепла в общем приращении энтальпий рудничного воздуха составляет 4-12 \%. Это влияние частично компенсируется отводом 2-8 \% общего количества тепла трубопроводами холодной воды.

Принято, что по всей длине горной выработки температура, относи-тельная влажность, плотность, энтальпия и влагосодержание воздуха изменяются линейно, В период исследований в замерных пунктах площадь поперечного сечения горной выработки оставалась постоянной.

При движении в горных выработках меняется внутренняя энергия воздуха из-за процессов тепло- и массообмена с горным массивом и шахтными водами. Любое изменение внутренней энергии воздуха можно оценить изменением его энтальпии 


$$
i=C_{p}+0,001\left(2501+1,93 t_{c}\right) d
$$

где $\mathrm{C}_{\mathrm{p}}$ - изобарная теплоемкость воздуха; $\mathrm{t}_{\mathrm{c}}$ - температура воздуха по сухому термометру; $\mathrm{d}$ влагосодержание воздуха.

Кроме кинетической энергии движения молекул, которая макроскопически выражена температурой, энтальпия характеризует потенциальную энергию взаимодействия этих молекул. Потенциальная энергия зависит от количества молекул воды в воздухе, макроскопически выражена влагосодержанием и характеризует тепловой эффект фазового превращения. Следовательно, можно нанисать

$$
\begin{gathered}
i_{q}=c_{p} t_{\mathrm{c}} \\
i_{m}=0,001\left(2501+1,93 t_{\mathrm{c}}\right) d
\end{gathered}
$$

где $\mathfrak{i}_{q}, \mathfrak{l}_{\mathrm{m}}$ - соответственно внутренняя кинетическая и потенциальная энергии воздуха.

В трехкомпонентной системе «горный массив - шахтная вода - рудничный воздух" перераспределение энергии может происходить несколькими пу-тями (конвекция, кондукция, испарение, конденсация). Во всех случаях энергию отдают компоненты с высокими значениями потенциалов переноса. В зависимости от направления потоков тепла и массы этот процесс может осуществляться по нескольким схемам. С учетом специфики теплового режима выработок глубоких шахт практический интерес имеют только те схемы, для которых поток тепла, независимо от направления потока массы, направлен от компонентов игорный массив - шахтная вода" к рудничному воздуху. В этих случаях компоненты «массив - вода" отдают основную часть энергии, необходимую для фазового превращения.

После умножения формул (1)-(3) на среднее весовое количество рудничного воздуха $\bar{G}$ получим

$$
\begin{gathered}
Q=Q_{q}+Q_{m} ; \\
Q_{q}=\bar{G} c_{p} t_{c} ; \\
Q_{m}=0,001 \bar{G} r d,
\end{gathered}
$$

(4)

(5)

где $\mathrm{Q}, \mathrm{Q}_{\mathrm{q}}, \mathrm{Q}_{\mathrm{m}}$ - соответственно общая, «явная" и “скрытая” теплота воздуха; $\mathrm{r}$ - удельная энтальпия парообразования при температуре $t_{c}$.

Таким образом, полная внутренняя энергия некоторого количества воздуха $\bar{G}$ представляется как сумма «явной" и «скрытой” теплоты. На основе формул (5) и (6) можно определить приращение этих видов теплоты для участка горной выработки: 


$$
\begin{aligned}
& \Delta Q_{q}=\bar{G} c_{p} \Delta t_{c} ; \\
& \Delta Q_{m}=0,001 \bar{G} r \Delta d .
\end{aligned}
$$

С другой стороны, при помощи коэффициентов нестационарного тепло- и массообмена можно написать

$$
\begin{aligned}
\Delta Q_{q} & =K_{\tau} P L\left(\bar{t}_{\mathrm{II}}-\bar{t}_{\mathrm{c}}\right) ; \\
\Delta Q_{m} & =0,001 K_{\tau m}(P L-F)\left(\bar{\theta}_{\mathrm{rI}}-\bar{\theta}\right) r,
\end{aligned}
$$

где $\mathrm{K}_{\tau}, \mathrm{K}_{\mathrm{tm}}$ - коэффициенты нестационарного тепло- и массообмена; P - периметр выработки; $\mathrm{L}$ - длина участка; $\bar{t}_{\Pi}, \bar{t}_{\mathrm{C}}$ - средняя температура соответственно горного массива и воздуха в пределах участка; $F$ - площадь поверхности шахтной воды; $\bar{\theta}_{п}, \bar{\theta}$ - средние потенциалы влагопереноса соответственно горного массива и рудничного воздуха в пределах участка.

В формуле (9) не дифференцируется теплоотдача с открытой поверхности шахтной воды, поскольку ее ости воды можно определить с большой точностью. Поэтому в формуле (10) оно дифференцируется. Следовательно, необходимо дифференцировать также влагоприращение воздуха в пределах участка:

$$
\Delta \mathrm{d}_{\mathrm{m}}-\Delta \mathrm{d}-\Delta \mathrm{d} \omega
$$

где $\Delta \mathrm{d}_{\mathrm{m}}, \Delta \mathrm{d} \omega$ - влагоприращения рудничного воздуха, обусловленные соответственно влагообменом и испарением.

С учетом вышеизложенного формула (8) принимает вид

$$
\Delta Q_{m}=0,001 \bar{G} r \Delta d_{m}
$$

После сопоставления формул (7), (9) и (10), (11) получим

$$
\begin{aligned}
& K_{\tau}=\frac{\bar{G} \Delta t_{c} c_{p}}{P L\left(\bar{t}_{\mathrm{n}}-\bar{t}_{\mathrm{c}}\right)} ; \\
& K_{\tau_{m}}=\frac{\bar{G} \Delta d_{m}}{(P L-F)\left(\bar{\theta}_{\mathrm{r}}-\bar{\theta}\right)} .
\end{aligned}
$$

Таким образом, изменение температуры рудничного воздуха является результатом действия энергии, подводимой термические путем (теплопроводностью), а изменение влагосодержания рудничного воздуха - следствием передачи энергии нетермическим путем (влагопроводности)), независимо от природы сил, за счет которых происходит указанное изменение. 
Однако способность горного массива проводить тепло и массу отнюдь не исключает ни в глубине, ни на границе массив - воздух превращения энергии из одного вида в другой.

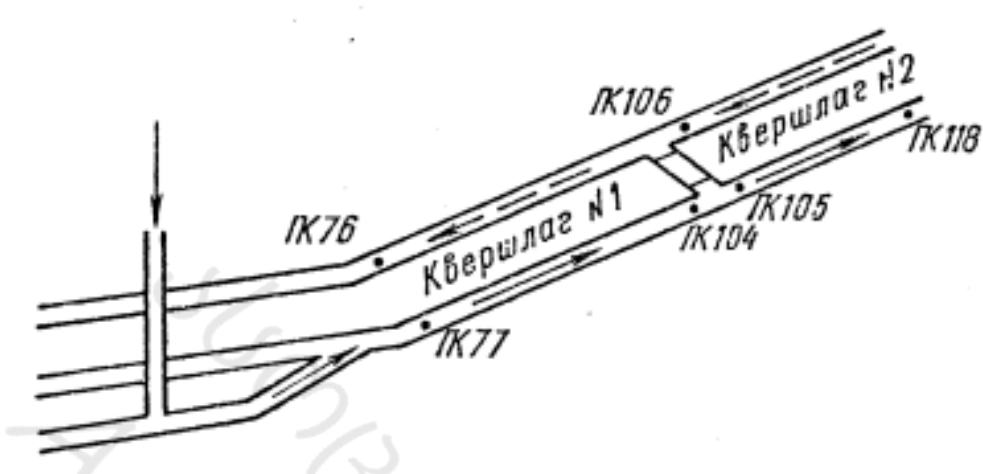

Рис.1. Схема расположения квсрицлагов шахты „Западная-2”

В самом деле, «чистой” теплопроводностью пористая среда никогда не характеризуется и градиент температуры всегда порождает дополнительный градиент потенциала массопереноса и, наоборот. Несмотря на это, разделение указанных процессов на две простые составляющие позволяет с некоторым приближением составлять и решать дифференциальные уравнения тепло- и массопереноса для любой замкнутой системы и, наконец, без разделения невозможна экспериментальная проверка полученных теоретических результатов. Исключительно положительным признаком выражений (12) и (13) является то, что все входящие в них валичины можно оп ределить экспериментально.

На опытных участках шахты «Заладная-2” в пикетах были оборудованы замерные пункты (рис.1) В квершлаге №2 полностью отсутствовали источники тепла и влага.

Результаты исследований представлены на рис.2.

Потенциал влагопереноса рудничного воздуха в конце расчетного участка

$$
\theta_{2}=\theta_{1}+\frac{K_{\tau m} P L\left(\bar{\theta}_{\Pi}-\bar{\theta}\right)}{\bar{G} c_{m}},
$$

где $\theta_{1}$ - потенциал влагопереноса рудничного воздуха в начале расчетного участка; $\mathrm{Cm}_{\mathrm{m}}$ коэффициент изотермической влагоемкости горных пород.

Равновесная влагосодержанию горного массива относительная влажность воздуха определена согласно кривым сорбции, составленным в лабораторных условиях ${ }^{1}$. По значению равновесной относительной влажности $\varphi$ вычислены значения потенциала влагопереноса для горнего массива

$$
\theta=R T \operatorname{In} \varphi
$$

где $R$ - универсальная газовая постоянная.

${ }^{1}$ С участием к.т.н. М.В. Ноникашвили и Ц. А. Церетели. 
a)
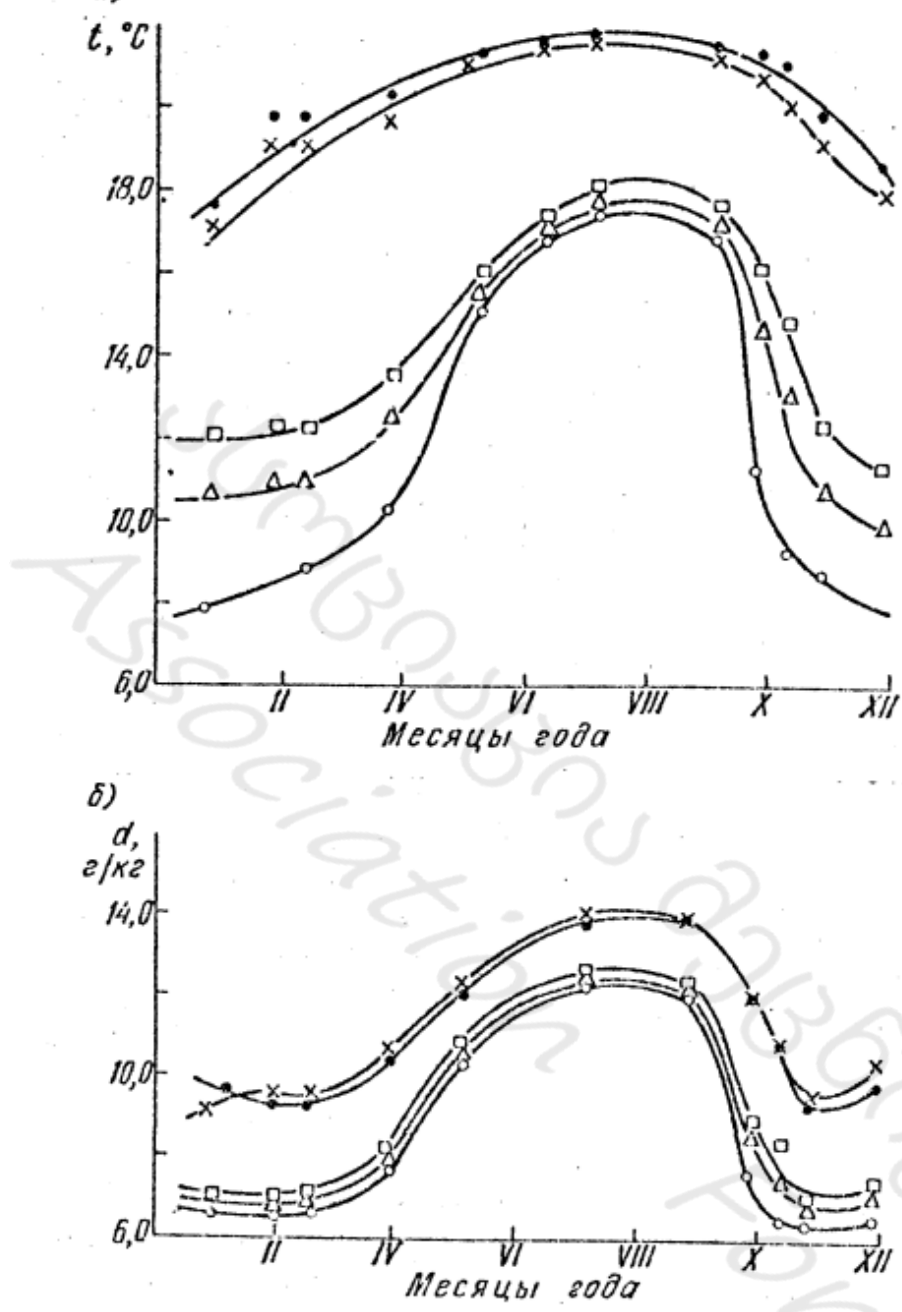

b)

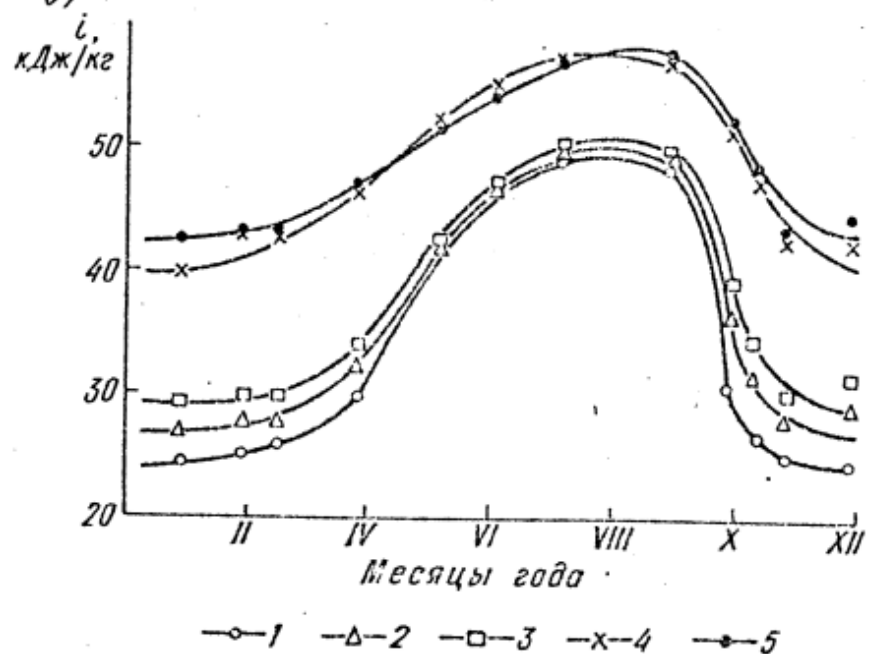

Рис.2. Годорое изменение лараметуов рудничного воздуха: а - температуры; 6 - влагосодержания; в - эн1 - ПК 77; 2 - ПК 101, 105; 3 - ПК 118; 4 - ПК 103;

$$
\text { 5 - ПК } 76
$$

Относительная влажность воздуха в конце участка

$$
\varphi_{2}=\exp \theta_{2} / R T_{2},(I 6)
$$

где $\mathrm{T}_{2}$ - температура рудничного воздуха в конце расчетного участка.

К сожалению, нам не удалось установить закономерности в годовом колебании значений коэффициента нестационарного массообмена, определенных по формуле (13). Очевидно, что при фундаментальном изучении массообменных процессов в горных выработках, с точки зрения образования осушенных зон или влагоуравнивающих оболочек, массообмен с горным массивов и коэффициент $\mathrm{K}_{\mathrm{rm}}$ имеют основополагающее значение. По всей вероятности, необходимы белее глубокие теоретические и экспериментальные исследования массообменных процессов и определение достоверных значений коэффициента $\mathrm{K}_{\mathrm{rm}}$, пригодных для практического применения. До этих исследований можно воспользоваться известные соотношением между безразмерным потенциалом переноса и соответствующим коэффициентом тепло- или массоотдачи (3), Безразмерный потенциал массопереноса на стенках горной выработки в зависимости от значений критериев Фурье, Био и Посноза приведен в работе [2].

Экспериментальные значения коэффициента нестационарного теплообмена $\mathrm{K}_{\tau}$ (рис. 3) определены

по формуле (12), а теоретические - согласно работе [4]. 
При определении теоретических значений $\mathrm{K}_{\tau}$ подставлялось реально измеренное значение скорости воздушного потока, которая зависит от времени года и изменяется из-за влияния естественной тяги.

Особо следует остановиться на поправке к коэффициенту нестационарного теплообмена. Известно, что все аналитические выражения коэффициента нестационарного теплообмена получены при допущении, что температура воздуха постоянна. Однако температура претерпевает существенное изменение во времени. Поправка, учитывающая годовое колебание температуры, определяется по выражению [4]

$$
\Delta K_{\tau}=A F(\tau)
$$

где $A=\Delta t /\left(\bar{t}_{\mathrm{m}}-\bar{t}_{\mathrm{c}}\right) ; F(\tau)$ - сложная функция времени проветривания; $\Delta t$ максимальное отклонение средней температуры рудничного воздуха в интересуемый период года от среднегодового его значения в пределах той же выработки.

В работе [4] функция $F(\tau)$ и поправка $\Delta К \tau$ были номограммированы в зависимости от комплекса А и месяца года. Сложная зависимость, существующая между $F(\tau)$ и $\mathrm{A}$, принята линейной. Поэтому при экстраполировании номограммы для больших А авторы получили результаты, не отражающие реальную картину годового изменения интенсивности теплообменных процессов в шахтах (см. рис.3, кривые 3). Согласно нашим исследованиям, зависимость функции $F(\tau)$ от комплекса А носит экспоненциальный характер. Построенная номограмма (рис.4) отражает реальную картину протекания этого процесса в шахтах Ткибули с учетом годового колебания температуры рудничного воздуха.

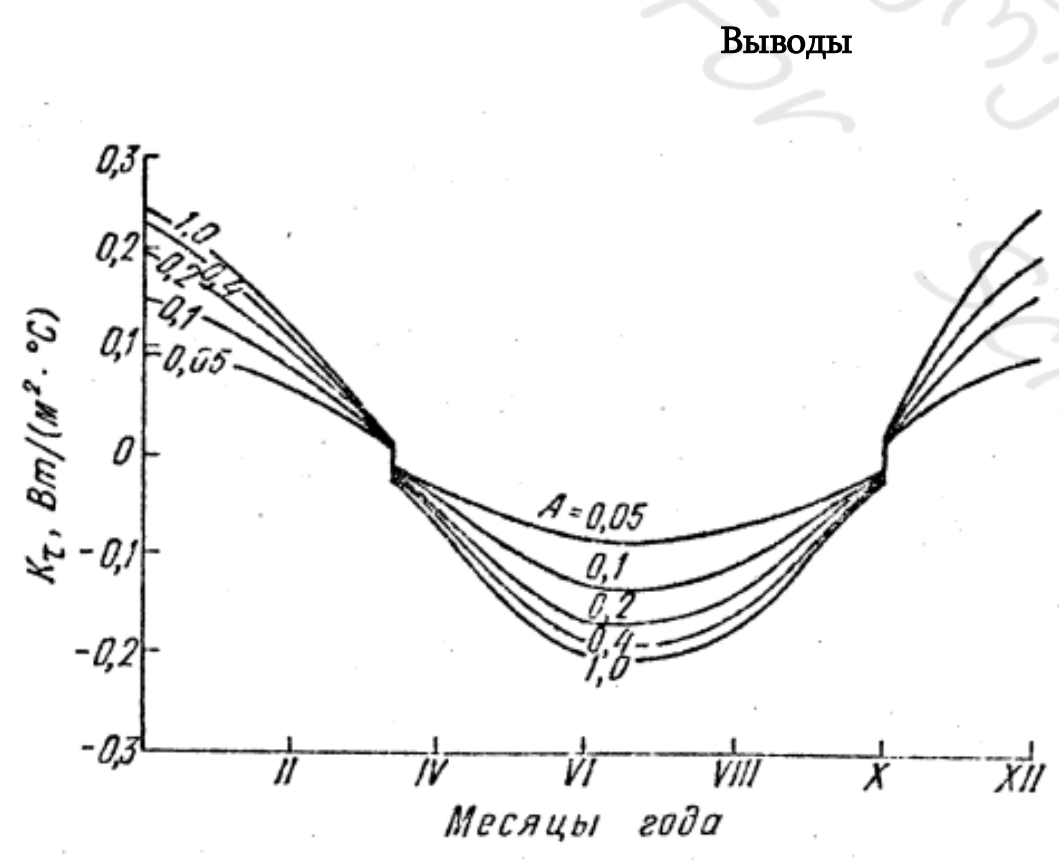

Рис.4. Номограмма пля опроделен яя погравки к коэффиииенту нестационарного төнлообмена
1. Амплитуда годового колебания влагосодержания рудничного воздуха практически не зависит от длины горных выработок. 2. С увеличением длины горных выработок амплитуда колебания температуры воздуха неуклонно уменьшается. Однако приращение энтальпии воздуха в капитальных выработках в течение года неодинаково.

3. Амплитуда годового колебания относительной влажности с увеличением длины горных выработок увеличивается, достигает максимума и в выработках с 
отработанным рудничным воздухом сохраняет практически постоянное значение в течение года.

4. Согласно экспериментальным наблюдениям, коэффициент нестационарного массообмена минимальное значение имеет в теплый период года. В выработках со свежим воздушным потоком его годовое колебание носит слокный характер. В выработках же с отработанной струей оно имеет вид близкий к синусоидальному. Проведенные нами эксперименты не позволяют определить значения $\mathrm{K}_{\mathrm{rm}}$ для заданного периода года с необходимой точностью.

5. Коэффициент нестационарного теплообмена имеет минимальное значение в теплые месяцы года, в холодные месяцы - его численное значение возрастает белее чем на порядок. Теоретические формулы дают либо постоянные значения указанной величины в течение года, либо ее максимум в летние месяцы. Составленная нами номограмма позволяет получить поправку, обеспечивающую согласование результатов теоретических расчетов с данными эксперимента.

6. В подавляющем большинстве случаев с открытой поверхности шахтной воды испаряется 3-20 \% общего количества влаги, воспринимаемого рудничным воздухом при его движении в горных выработках. Основную часть влага рудничный воздух принимает от горного массива. Формирование микроклимата в капитальных выработках происходит, главным образом, за счет теплообменкых процессов, массообменше процессы имеют второстепенное значение,

\section{ЛИТЕРАТУРА}

1. Единая методика прогнозирования температурных условий в глубоких шахтах. Макеев- ка-Донбасс, изд. МакНИИ, 1979.

2. Ониани Ш.И., Ланчава О.А., Ксоврели Ю.Р. Обобщенные зависимости изотермического массопереноса в системе горный массив - рудничный воздух. Сообщения АН ГССР, 1981, т. 106. № 1.

3. Ониани Ш.И., Ланчава О.А. Критериальные кривые для теплового расчета горных выработок с термами. - Сообщения-АН ГССР, 1975, т. 77, № 1.

4. Щербань А.Н., Кремнев О.А., Журавленко В.Я. Руководство теплового режима шахт. М., Недра, 1977. 